\title{
Metáfora y pandemia
}

\section{Ricardo Sigala ${ }^{1}$}

\section{Contribución en la Sección Panorama Social}

Resumen: Ante las incógnitas y la incertidumbre que aparecen con el surgimiento de una nueva enfermedad y su expansión a nivel de pandemia, surgen discursos y metáforas que intentan explicarla o por lo menos contenerla a nivel ideológico. Los discursos emanan de los médicos y los científicos hacia instituciones como el Estado y la Iglesia para después pasar a los medios de comunicación, y una vez en las redes sociales se propagan en una especie de contagio discursivo. Estos discursos más que explicar el fenómeno crean una realidad semántica alimentada del acervo ideológico histórico y contemporáneo, portador de valores o prejuicios, por lo que en el escenario de la producción discursiva se pueden presentar alternativas ante los discursos dominantes.

\section{La metáfora en la comunicación}

La metáfora es un recurso ineludible de comunicación, y a diferencia de lo que una mirada superficial pudiera indicar, forma parte de nuestros discursos cotidianos, incluso de las ciencias. El lenguaje tropológico no se limita a ser un recurso literario. En el periodismo abundan los ejemplos. En las notas informativas tenemos cabezas, entradas, ventanas, cuerpos del texto, recurrimos a fuentes, escribimos columnas, y algunos medios cuentan con las mejores plumas. Esas metáforas sirven para designar realidades concretas y no requieren de un proceso de decodificación hermenéutica para interpretarlas, como podría suceder con la poesía; estas metáforas, o tropos o símiles, sirven para que nos podamos comunicar de manera más eficiente y no guardan la posibilidad de ambigüedad. Son palabras que han fijado su significado y no son leídas desde una posibilidad polisémica.

\section{La metáfora en la medicina}

Algo similar ocurre con la ciencia de la medicina, y en particular con algunas enfermedades. Más allá de la típica construcción de tecnicismos: de las palabras griegas cardios (corazón) y patos (enfermedad), resulta cardiopatía (enfermedad del corazón); o de gaster (vientre o estómago) e -itis (inflamación), deriva en gastritis (inflamación del

\footnotetext{
1 Profesor del Centro Universitario del Sur. Universidad de Guadalajara. Correo electrónico: ricardo.sigala@cusur.udg.mx
} 
estómago), existen también otros mecanismos para la construcción de palabras basados en el símil o la comparación. Pensemos sólo en unos pocos ejemplos. El caso del cáncer es oportuno, Hipócrates definió cierto tipo de úlceras malignas por su parecido con el cangrejo, (karkínos). "El tumor, con el racimo de vasos sanguíneos inflamados en su torno, recordaba a Hipócrates un cangrejo enterrado en la arena con las patas extendidas en círculo" (Mukherjee, 2011, p. 75). Otro ejemplo es el de las enfermedades venéreas, cuyo adjetivo se deriva de la diosa venus, en relación a su connotación sexual, en su condición de diosa del amor carnal.

Las metáforas o comparaciones no siempre son inofensivas. Su uso delata formas de pensar arraigadas en los hablantes, y esas formas de pensar son portadoras de prejuicios, estereotipos y, en ocasiones, hasta discursos de odio. En el año 1530 Girolamo Fracastoro, que era poeta y cirujano, publicó Syphilis sive morbus gallicus, en donde cuenta cómo el protagonista de su poema recibió como castigo una enfermedad sexual porque decidió dejar de adorar a Apolo y comenzó a rendirle tributo al rey. Esa enfermedad era la sífilis que, como alude el subtítulo del poema, era conocida como "la enfermedad francesa". En efecto entre los siglos XV y XVII, los diversos pueblos la nombraron haciendo alusión a sus enemigos históricos, y esas nominaciones manifestaron una declarada xenofobia. Italia, Alemania e Inglaterra la llamaban la enfermedad francesa; los franceses la denominaron el mal napolitano; los Países Bajos, Portugal y el norte de África le llamaron la enfermedad española; los japoneses se la atribuyeron a los chinos; los turcos la nombraron el mal cristiano; los alemanes y polacos se acusaron mutuamente al nombrarla. El adjetivo aludía al supuesto de que la enfermedad fue generada por el otro, el vecino, el enemigo en la guerra, o el infiel. Evidentemente este fenómeno se acrecienta cuando se trata de una de esas enfermedades "vergonzosas", de origen privado e íntimo, asociada principalmente a las relaciones sexuales.

En su libro Viajes virales, Lina Meruane, presenta un estudio de los discursos y las metáforas del VIH/SIDA en el continente americano, ahí registra que la enfermedad inicialmente fue llamada Gay Related Immuno Deficiency (GRID), en alusión a que se trataba de una enfermedad de los hombres que tenían prácticas homosexuales, y no fue sino hasta 1982 que recibió el término más neutral de VIH/SIDA (Meruane, 2012), lo que no impidió que ese grupo dejara de ser estigmatizado e incluso perseguido por razones asociadas a la enfermedad.

Como se puede apreciar, las metáforas que se usan en torno a las enfermedades manifiestan los prejuicios, los valores, los temores de los grupos que las producen, pero además generan respuestas que se pueden manifestar en forma de persecución, descrédito, xenofobia, intolerancia, o bien crean el espacio idóneo para el ejercicio desmedido del poder del Estado. 


\section{El internet y las metáforas}

La cibernética, y en especial internet, es un especio metafórico. El nombre mismo hace alusión a una red, y en ella se hospedan sitios, se sube y se baja información, aunque está claro que esa red es una abstracción, que no es un espacio real con lugares y que las relaciones de orientación como arriba y abajo son meras figuraciones. Cuando buscamos información en la internet decimos que navegamos y por supuesto es una fuente de información inagotable. Mucho se ha estudiado sobre la utilidad de las metáforas para la asimilación y familiarización de los usuarios a nuevas tecnologías "para entender una cosa en términos de otra" (traducción propia de Núñez Mosteo, 2004, p. 2),

La internet no sólo es un espacio en el que abunda el lenguaje metafórico, sino que además es prolijo en metáforas asociadas al campo de la enfermedad. El software usado con el fin de alterar el funcionamiento de un aparato es llamado virus (virus cibernético para diferenciarlo del biológico) que simbólicamente infecta el sistema y para solucionar dicho problema se hace necesaria una vacuna, es decir un antivirus. La metáfora no es caprichosa ni arbitraria, pues la capacidad de diseminarse de esos virus es exponencial, muy parecido a como sucede con las enfermedades infecciosas. Este uso de la palabra virus es llevado también a otro ámbito, el de la información, publicaciones, videos, etc., que se popularizan de manera rápida, así, por ejemplo, decimos que un video se hizo viral.

Las publicaciones en internet, y particularmente en las redes sociales, son el escenario de tendencias en las que la información se disemina / esparce por todo el planeta, esto no sería un problema si esas publicaciones no fueran con mucha frecuencia información errónea, inexacta o falsa, y en un contexto de pandemia esto puede ser un problema de importantes dimensiones.

El escenario es el de la pandemia y la gran cantidad de información de un tema en específico que circula en internet, usualmente este fenómeno encuentra un medio para su expresión en las redes sociales y se asocia a las fakenews o infoxicación, o para seguir con las metáforas de tipo médico, se ha acuñado el concepto de infodemia. En términos metafóricos la información falsa o errónea se difunde como una enfermedad y adquiere dimensiones, primero, de epidemia, y después, de pandemia. Ante este riesgo las instituciones y el periodismo juegan un papel valioso para hacer un contrapeso por medio de la generación de información real, veraz, documentada. Frente a la espontaneidad de las redes sociales se hace presente el trabajo periodístico que corrobora, contextualiza, se apega a la verdad con base en un código ético.

Cuando aparece una nueva enfermedad, en especial si tiene una expresión pandémica, la comunidad científica y médica comienza a producir un lenguaje que se extiende primero a los políticos y a la Iglesia para después ser desplegado en los medios de 
comunicación masiva. Ese lenguaje puede estar constituido por metáforas y por discursos que tienen como objetivo intentar explicar la epidemia, pero que también quiere contener retóricamente a la enfermedad, y al hacer eso lo está instrumentando por la vía ideológica (Meruane 2012).

Cuando en los primeros meses del 2020 se comenzó a manifestar la pandemia de Covid-19 también comenzaron a difundirse ciertos discursos asociados a su origen como que alguien había comido una sopa de murciélago, o que el virus se originó en los pangolines, o que estaba asociada a los viajeros, entre otros muchos discursos de origen especulativo como el castigo divino, la consecuencia del deterioro ecológico y las conspiraciones. Cuenca (2020), realizó una investigación al respecto, en el primer trimestre del año ya había encontrado en internet cincuenta símiles en inglés partiendo de la expresión "Coronavirus (o COVID-19) is like", entre las expresiones que destaca en un artículo publicado en el sitio The Conversation. Academic rigor, journalistic flair están algunos de origen religioso como "el coronavirus es una plaga bíblica", o bien otros relacionados con desastres naturales de tipo climatológico como "el coronavirus es como un tsunami" o "El coronavirus es un huracán que se mueve muy lentamente". Pero el que más llama la atención es en el que lo compara con una guerra, porque no sólo ha sido una metáfora que ha sido usada en los países de lengua inglesa, sino también otros idiomas occidentales como el español o el alemán. Desde ese símil los soldados serían los trabajadores de la salud, el enemigo, el virus y el campo de batalla, los hospitales; incluso la analogía puede ir más allá: "que si los ciudadanos somos los soldados contra nuestro enemigo común, el virus, que si unidos lo venceremos, que si hay que atacarlo con toda la munición, que si luchamos desde casa, que es nuestra trinchera" (Cuenca, 2020, pár. 8).

En los medios de comunicación y en los comunicados oficiales se habla de que los médicos asignados a las clínicas Covid son el personal de primera línea, el virus no infecta, sino que ataca y los pacientes que superan la enfermedad no sanan, sino que vencen al Covid-19, o en su defecto aquellos que mueren han sido víctimas o han perdido la batalla.

Meruane observa que en la construcción de los discursos de la enfermedad se pueden manifestar dos vías ideológicas, por una parte metáforas o discursos con un objetivo moralizante o represivo, y por otra una oposición que busca desactivar procesos estigmatizadores o autoritarios o simplemente políticamente incorrectos (Meruane 2012). Ejemplos de lo anterior son los casos ya presentados de la sífilis y el VIH/SIDA, o bien el brote epidémico que surgió en 2009, llamado Gripe porcina, y que terminó recibiendo la acepción de gripe H1N1. En el proceso se pasa de una estigmatización que sugiere el origen de una enfermedad en un grupo étnico, nacional, religioso, una preferencia sexual, o una especie animal, a nominaciones que buscan desactivar dichos procesos. 
En el caso de la metáfora bélica aplicada a la pandemia de Covid-19, las reacciones no se hicieron esperar. Desde el mes de marzo un grupo de académicos españoles lanzaron una propuesta que incluía la utilización del hashtag \#ReframeCovid ("cambiar el enfoque de la COVID"), con el objetivo de motivar alternativas frente al discurso bélico asociado a la enfermedad. Ceccarelli (2020), escribe: "Las primeras críticas a la retórica de la COVID-19 advierten sobre el uso de metáforas bélicas que pueden acercarnos a un sentimiento autoritario y nacionalista, evocando a la xenofobia y al racismo" (pár. 3)

No sólo el mundo académico ha reaccionado a la incorporación del discurso de la guerra al acervo metafórico de la Covid-19, también un sector del ámbito médico se ha pronunciado al respecto. En el portal Investigación y ciencia se lee un artículo de Wise (2020) titulado en el que, luego de mostrar su desacuerdo con el discurso bélico en su disciplina, la autora agrega: "no estamos en guerra y, ciertamente, no nos hemos alistado a ningún ejército. Somos médicos. Lo que hacemos es trabajar a destajo para mantener con vida a nuestros pacientes." (pár. 2). Wise (2020) asevera que al adoptar una mentalidad de guerra se corre el riesgo de asumir que "todo se vale" y que la reflexión pasa a segundo término para dar lugar a la obediencia ciega, que "avala el caos y la suspensión del Estado de Derecho a cambio de una solución rápida" (pár.8). También puntualiza que "la mentalidad de guerra requiere que haya muerte, sufrimiento y abnegación al servicio de la patria, pero una pandemia no debe exigirle tal sacrificio al personal sanitario" (pár. 11). Un punto que destaca es que la guerra es por naturaleza una situación de peligro y de riesgo que "jamás debe ser inherente a un hospital" (pár. 11). Esta postura muestra las implicaciones del discurso bélico asociado ya no al ámbito social, sino de manera más precisa a la práctica de la medicina.

Las críticas al discurso bélico son claras y manifiestas, no obstante, las alternativas no han corrido con suerte pues no han logrado arraigar en el uso institucional ni en los medios y por lo tanto tampoco en las redes sociales y el uso cotidiano de la lengua. Ceccarelli habla de la metáfora del viaje, en la que podemos imaginar la solución de la pandemia como un regreso a casa, más que como un triunfo de las armas, o bien la metáfora que utilizó el papa Francisco de "remar juntos" (Vatican News, pár. 3). Quizás el problema de este tipo de propuestas radique en la paradoja que supone por una parte imaginar el problema en términos de viaje, movimiento y mundo exterior ante una situación de encierro y confinamiento. Por otra parte, se encuentran postura como la que observa Silvera Roig (2020), quien afirma que la metáfora es un instrumento lingüístico que tiene a su favor facilitar la asimilación emocional del sentido y su énfasis semántico, pero que no deja de ser sólo una herramiento lingüística "que guía significados, no los contiene" (pár. 9) y que "las metáforas no funcionan igual para todos y que la metáfora de guerra puede ser motivadora para muchas personas que sufren una enfermedad" (pár. 11) y que una metáfora se puede conceptualizar de distintas formas. 
Estas divergencias encontradas muestran lo que Treichler llamó: "el ensamblado caótico de nuestra comprensión de la epidemia" (recuperado por Meruane, 2012, p. 23), pues justo la falta de claridad en el tema, la falta de certeza médica y científica, es la que hace que surjan estas divergencias. Así pues, se hace necesario observar atentamente, pues estos discursos más que representar la realidad, son un intento de construirla. Son un artefacto cultural nacido la necesidad de explicar esa nueva realidad difícilmente asible. Esas imágenes propuestas surgen de los componentes del pasado que manifiestan prejuicios históricos y recientes, y que a la vez generan nuevas formas de percibir el mundo. Este repertorio metafórico se vuelve excesivamente contagioso debido a la ideología subyacente, y hoy en día con el uso de las redes sociales se magnifica.

\section{Referencias}

Ceccarelli, L. (28 de mayo de 2020). COVID-19: las metáforas de la pandemia. The Mètode website. https://metode.es/revistas-metode/opinio-revistes/especial-covid-19es/covid-19-las-metaforas-de-lapandemia.html?fbclid=IwAR2Sshe2BSV33SJsYoeXL3L2uvAZinW0wemI5XIDWf W6S72XD2QyWueFFIg

Cuenca, M. J. (25 de abril de 2020). ¿Cómo es el coronavirus? Metáforas y símiles para una pandemia. The Conversation website. https://theconversation.com/como-esel-coronavirus-metaforas-y-similes-para-una-pandemia-136533?fbclid=IwAR3V87RJHv0bQz2k9p50vPiS7-RbO9zUTlik5kpP294CV5x5P73e-vs2IM

Fracastoro, G. (1530). Syphilis, sive morbus gallicus. Verona.

Meruane, L. (2012). Viajes Virales. Fondo de Cultura Económica.

Mukherjee, S. (2011). El emperador de todos los males: una biografía del cáncer. Taurus

Núñez Mosteo, F. (2004). Metàfores d'Internet. Digithum, (6). https://www.raco.cat/index.php/Digithum/article/view/18524

Silvera Roig, M. (29 de abril de 2020). ¿Guerra contra el Covid-19? No culpes a la metáfora. El Confidencial-Opinioón, Tribuna. https://blogs.elconfidencial.com/tecnologia/tribuna/2020-04-29/guerra-covid-19metafora_2570808/?fbclid=IwAR12YRqFgnfHDVNAnhb3ZmNoZSdOzt9BhIBgxZ InJhXbO4EulYaHiQ9rHN4

Vatican News (27 de marzo de 2020). Homilía completa del Papa Francisco en el momento extraordinario de oración por la pandemia. 
https://www.vaticannews.va/es/papa/news/2020-03/homilia-completaoracionextraordinaria-papafrancisco-coronavirus.html

Wise, A. (24 de abril de 2020). Las metáforas bélicas distorsionan la realidad de la COVID19. Investigación y Ciencia website, Opinión-Actualidad https://www.investigacionyciencia.es/noticias/las-metforas-blicas-distorsionan-larealidad-de-la-covid-19-18571 ?fbclid=IwAR32jN8wSIFcRMQwShslda5mG_p2oNcaMSroxVDkNbcdKMbl147YpFY8PE 